\title{
Assessment of interannual and intra-annual atmospheric dispersion variability parameters in the Belorussian NPP siting area
}

\author{
Fedor Bryukhan ${ }^{1 *}$ \\ ${ }^{1}$ Moscow Moscow State University of Civil Engineering, 129337, 26, Yaroslavskoye Shosse, \\ Moscow, Russia
}

\begin{abstract}
Identification of atmospheric boundary layer (ABL) radionuclide dispersion conditions, which are characterized by $\mathrm{ABL}$ dispersion parameters, plays an important role in evaluating the radiation safety of nuclear power plants (NPPs) and establishing engineering protection thereof. Therefore, the ABL status monitoring observations are launched at the stage of in-situ NPP construction. When analyzing and predicting radiation situation in the NPP vicinity areas, it is of great importance to determine the parameters of atmospheric dispersion variability with time. The ABL status monitoring at the Belorussian NPP site has been carried out since September 2014 by means of acoustic and radio-acoustic sounding of the ABL. The present study is aimed at assessing interannual and intra-annual variability of atmospheric dispersion parameters in the Belorussian NPP siting area on the basis of the monitoring data. The relative interannual stability of the main average annual atmospheric dispersion characteristics (vertical temperature gradient, wind speed and direction) over the observation period has been revealed. At the same time, the average seasonal values of the dispersion parameters are characterized by significant fluctuations thereof during the annual course. The prospects of the ABL status monitoring for other potentially hazardous industrial facilities, such as thermal power plants and chemical plants, are also noted.
\end{abstract}

\section{Introduction}

Atmospheric dispersion is a combination of pollutants transport in the atmosphere by directed air flow and turbulent diffusion, and thus its comprehensive study is of great importance for environmental applications. In particular, the dispersion parameters of the atmospheric boundary layer (the lower atmospheric layer, extending to heights of about 1 $\mathrm{km}$ ) determine the conditions of the radionuclide dispersion and are therefore important in assessing the radiation safety and developing engineering protection of NPPs [1]. In this regard, the atmospheric boundary layer (ABL) status monitoring is provided at the key stages of the NPP life cycle (during construction, operation and decommissioning thereof).

\footnotetext{
Corresponding author: pniiis-gip@mail.ru
} 
The main purpose of such monitoring is to determine the ABL dispersion characteristics required to assess the radiation safety of NPPs, to predict and identify trends in these characteristics over time, as well as to develop recommendations aimed at reducing the NPPs' adverse impact on the environment.

In recent decades, in the world practice and in Russia, monitoring of the ABL state is usually carried out by means of acoustic and radio-acoustic sounding of the atmosphere with the help of sodars (SODAR) and RASS systems [2-3]. Combined measurement systems consisting of sodars supplemented with RASS (SODAR/RASS) systems allow remote recording of vertical profiles of the wind vector and temperature in the lower atmospheric layer extending to heights of 600-1000 $\mathrm{m}[4,5]$.

The present study is aimed at assessing interannual and intra-annual variability of atmospheric dispersion parameters in the Belorussian NPP siting area on the basis of the monitoring data observed over the last 4 full years (from 2015 to 2018). The initial data for this study were the results of the ABL status monitoring observations carried out from September 2014 to the present time by the Scientific \& Industrial Association Gidrotekhproekt, with the involvement of experts from the Moscow State University of Civil Engineering and GrafProektStroyIziskaniya Ltd. The climatic regime of atmospheric dispersion in the Belarusian NPP siting area was studied earlier in the framework of engineering surveys using radiosonde observations [6].

\section{Methodologies}

The SODAR/RASS observation system provides for continuous measurements of air temperature, as well as wind speed and direction, which are the meteorological characteristics that determine the atmospheric dispersion conditions. The monitoring system also ensures automatic recording and accumulation of measurement results. The monitoring system set up at the site of the Belarusian NPP under construction includes an observation subsystem and a data processing subsystem [5]. Ongoing processing of the measurement results involves maintaining a database and calculating a set of the $\mathrm{ABL}$ dispersion characteristics using the specially developed software.

The observation subsystem is a SODAR/RASS complex developed by METEK GmbH (Germany) [7]. In August 2014, measuring equipment was mounted and installed at a weather station in the village of Markuny located $4.5 \mathrm{~km}$ northeast of the NPP site. Upon completion of the equipment adjustment and commissioning, continuous monitoring of the ABL state was launched which is going on to date. The ABL parameters are automatically measured and recorded every 10 minutes.

The data processing subsystem manages the measurement results, archives them, vertically interpolates the temperature and the wind vector, as well as calculates the $\mathrm{ABL}$ statistical characteristics, the key of which include the following:

1. average air temperature at various heights;

2. repeatability of atmospheric stability classes;

3. average values of the vertical temperature gradient in the vertical layers;

4. characteristics of surface and elevated temperature inversions;

5. statistical characteristics of the wind;

6. a set of joint repeatability of atmospheric stability classes, wind speeds and directions.

Calculation of the ABL characteristics is carried out for the current months, seasons and years. Reporting materials include arrays of statistical characteristics of atmospheric dispersion for individual seasons and years. The data on the ABL state accumulated over the last 4 full years make it possible to identify the specific features of interannual and intra-annual changes in the ABL dispersion characteristics. 


\section{Results and discussion}

The main ABL parameters that determine the atmospheric dispersion conditions include a vertical gradient of air temperature, atmospheric stability classes, modulus and direction of the wind vector. Graphs of interannual changes in these characteristics averaged over the current years are presented in Figures 1 and 2.
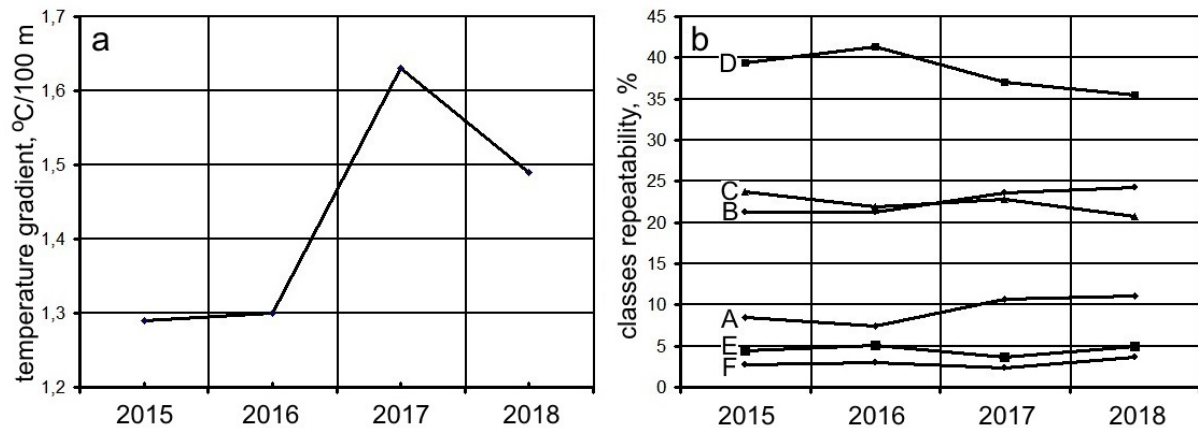

Fig. 1. Interannual changes in the average annual values of the air temperature vertical gradient in the layer of 0-300 $\mathrm{m}$ (a) and the repeatability of atmospheric stability classes (b).
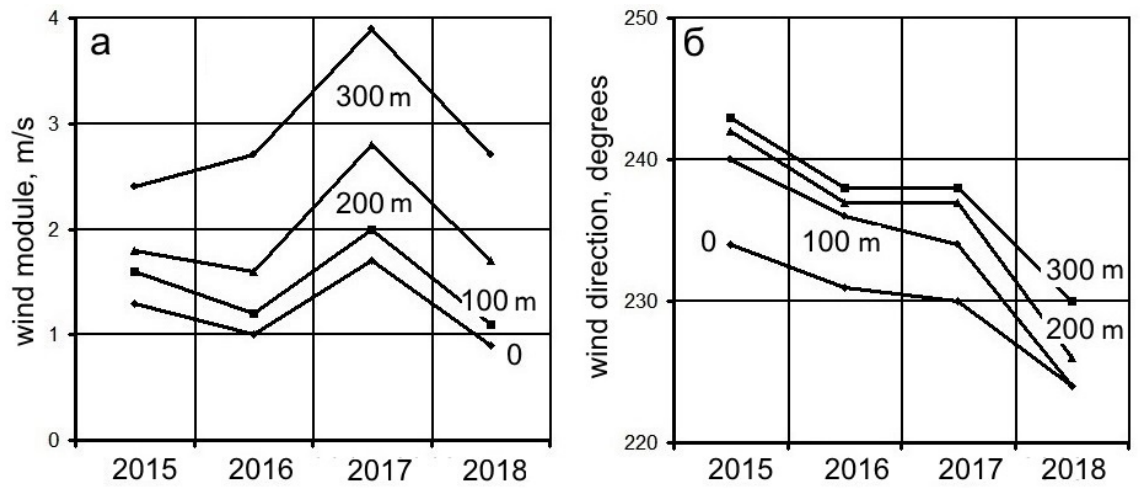

Fig. 2. Interannual changes in the modulus (a) and direction (b) of the average annual values of the wind vector at various heights in the atmospheric boundary layer.

According to Figure 1a, the vertical temperature gradient throughout the study period is positive (the temperature drops with height) and varies between $1.29-1.63{ }^{\circ} \mathrm{C} / 100 \mathrm{~m}$. Such temperature gradients characterize a high degree of atmospheric turbulence that is favorable to the dispersion of radionuclides. Figure $1 \mathrm{~b}$ shows the following atmospheric stability classes: $A$ - extremely unstable, $B$ - moderately unstable, $C$ - weakly unstable, $D$ - neutral, $E$ - weakly stable, and $F$ - stable. As follows from Figure $1 \mathrm{~b}$, throughout the entire observation period, the prevailing classes are $B, C$, and $D$ characteristic of favorable dispersion conditions. Adverse stability classes $(E$ and $F)$ are observed quite rarely, and their total repeatability does not exceed $12 \%$ [8].

Figure $2 \mathrm{a}$ shows that the wind vector modulus varies mainly within $1-4 \mathrm{~m} / \mathrm{s}$ while it rapidly grows with height. At the same time, interannual fluctuations in wind speed at a fixed height are insignificant and amount to about $1 \mathrm{~m} / \mathrm{s}$, which is commensurate with the measurement accuracy of the wind speed. According to the results presented in Figure 2b, the west-south-west winds prevailed throughout the entire study period of 2015-2018.

Thus, the relative stability of the main average annual characteristics of atmospheric dispersion is noted. Along with this, their significant fluctuations in the annual course are 
obvious. This is clearly shown by the data presented in Table 1. According to the results given in this Table, the air temperature gradient in the lower 300 -meter layer is positive. Its maximum is observed in the winter months and exceeds $2{ }^{\circ} \mathrm{C} / 100 \mathrm{~m}$, while the minimum of $0.8{ }^{\circ} \mathrm{C} / 100 \mathrm{~m}$ occurs in the summer months. In the transitional seasons (autumn and spring), the gradient varies in the range from 1.3 to $1.5^{\circ} \mathrm{C} / 100 \mathrm{~m}$. The total repeatability of adverse atmospheric stability classes $(E$ and $F$ ) increases from winter to summer from 4.5 to $11.3 \%$. In the transitional seasons, it is about $7 \%$. As for the wind, a significant rise in its speed with height and a relatively stable direction are typical of all seasons. In the annual course, there is a noticeable weakening of the wind speed from the winter to the spring and summer months. Along with this, the wind direction is characterized by relative stability with a predominance of the west-south-west direction.

Table 1. The annual course of the seasonal atmospheric dispersion characteristics averaged over the period of 2015-2018.

\begin{tabular}{|c|c|c|c|c|}
\hline \multirow[t]{2}{*}{ ABL dispersion characteristics } & \multicolumn{4}{|c|}{ Seasons } \\
\hline & Winter & Spring & $\underset{\mathbf{r}}{\text { Summe }}$ & Autumn \\
\hline $\begin{array}{l}\text { Temperature gradient in the } 0-300 \mathrm{~m} \\
\text { layer, }{ }^{\circ} \mathrm{C} / 100 \mathrm{~m}\end{array}$ & 2.05 & 1.52 & 0.81 & 1.32 \\
\hline \multicolumn{5}{|c|}{ Repeatability of stability classes, \%: } \\
\hline$A$ & 13.3 & 9.9 & 7.4 & 7.1 \\
\hline$B$ & 21.8 & 26.2 & 21.0 & 21.1 \\
\hline$C$ & 25.4 & 22.7 & 18.8 & 22.3 \\
\hline$D$ & 35.0 & 34.2 & 41.5 & 42.5 \\
\hline$E$ & 2.7 & 4.3 & 6.5 & 4.6 \\
\hline$F$ & 1.8 & 2.7 & 4.8 & 2.4 \\
\hline \multicolumn{5}{|c|}{ Wind vector modulus at $\mathrm{ABL}$ heights, $\mathrm{m} / \mathrm{s}$ : } \\
\hline 0 & 1.9 & 0.8 & 1.4 & 1.3 \\
\hline $100 \mathrm{~m}$ & 2.4 & 0.9 & 1.7 & 1.6 \\
\hline $200 \mathrm{~m}$ & 3.1 & 1.1 & 2.2 & 2.3 \\
\hline $300 \mathrm{~m}$ & 3.9 & 1.7 & 3.0 & 3.4 \\
\hline \multicolumn{5}{|c|}{ Wind vector direction, degrees: } \\
\hline 0 & 219 & 248 & 272 & 216 \\
\hline $100 \mathrm{~m}$ & 221 & 254 & 274 & 230 \\
\hline $200 \mathrm{~m}$ & 228 & 245 & 271 & 214 \\
\hline $300 \mathrm{~m}$ & 230 & 236 & 262 & 222 \\
\hline
\end{tabular}

At present, the Belarusian Republican Center for Hydrometeorology, Radioactive Contamination Control and Environmental Monitoring is completing the development of an automated system for radiation situation monitoring (ASKRO) in the Belarusian NPP siting area. It is planned to incorporate the ABL monitoring system described above as a part of the ASKRO developed.

The ABL status monitoring at the sites of the NPPs under construction and in operation is an effective means of obtaining input data for assessing the current characteristics of atmospheric dispersion. It should be noted that similar monitoring can be used for other potentially hazardous industrial facilities, such as thermal power plants, chemical plants, etc. that are characterized by a similar dispersion pattern of pollutants.

\section{Conclusions}

1. A study was made of the interannual atmospheric dispersion characteristics variability at the Belorussian NPP site for the period of 2015-2018 based on the data of remote 
measurements of the atmospheric boundary layer parameters using combined blocks of acoustic and radio-acoustic sounding systems of the atmosphere.

2. It has been established that the vertical temperature gradient throughout the study period is positive and characterizes a high degree of atmospheric turbulence, favoring the radionuclide dispersion. In this case, the repeatability of adverse atmospheric stability classes is insignificant and does not exceed $12 \%$. The wind speed is characterized by rapid growth with a height in the lower 300-meter layer of the atmosphere with prevailing winds of the west-south-west direction.

3. In general, there is a relative stability of the main average annual characteristics of atmospheric dispersion during the observation period of 2015-2018. Along with this, the average seasonal characteristics are noted by their significant fluctuations over the annual course.

4. It is noted that the atmospheric boundary layer status monitoring is also promising for other potentially hazardous industrial facilities, for example, thermal power plants and chemical enterprises.

\section{References}

1. F.F. Bryukhan, A.Yu. Vinogradov, A.A. Lavrusevich, At. Energ., 118, 365-368 (2015)

2. S. Bradley, Atmospheric acoustic remote sensing: Principles and applications (CRC Press, NY, 2008)

3. D. Khodzhaev, B. Normuminov, Y. Mustapakulov, A.Mottaeva, E3S Web of Conferences, 110, 01045, (2019) doi.org/10.1051/e3sconf /201911001045

4. M.A. Novitskii, N.F. Mazurin, L.K. Kulizhnikova et al., Rus. Meteorol. Hydro. 36, 693-699 (2011)

5. B. Hennemuth, G. Peters, H.-J. Kirtzel, Atmos. Meas. Tech., 5, 1399-1408 (2012)

6. F.F. Bryukhan, A.Yu. Vinogradov, A.A. Lavrusevich, Industrial and Civil Engineering, No. 2, 51-54 (2015)

7. A.F. Bryukhan, Proc. of the 5-th International Research and Practice Conference "European Science and Technology", 1, 345-350 (2013)

8. E. Vasilyeva, A. Mottaeva , E3S Web of Conferences, 91, 08051, (2019) doi.org/10.1051/e3sconf /20199108051 